\title{
Characterization of pore structure in Baode coals treated with saturated
}

\section{water and drilling fluid}

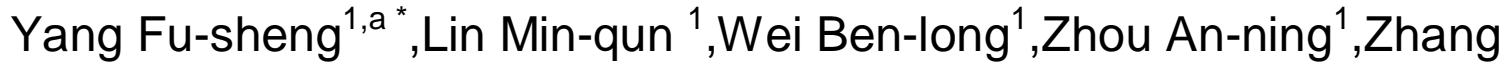 \\ Hui-jun ${ }^{1}$,Wang $\mathrm{Hao}^{2}$, Jing Yun-huan ${ }^{2}$,Yang Lei ${ }^{2}$, Ma Le-bo ${ }^{2}$ \\ (1. College of Chemical Engineering of Xi'an University of Science and Technology,Xi'an \\ 710054,China; 2. Shenhua Ningxia Coal Industry Group Co.,Ltd.,Yinchuan 750011,China) \\ a291656456@qq.com
}

Key words: coal; drilling fluid; pore structure; nitrogen adsorption; mercury injection

Abstract: For further research on microscopic pore characteristics and its geological accumulation significance of coal bed, coal samples from drilling holes of Baode, Shanxi province in China were collected to perform scanning electron microscopy (SEM), mercury injection and low-temperature nitrogen sorption-desorption experiments. It is shown that intergranular pores and transitional pores are main types, accompanied by obvious oval shaped pores and friction pores in Baode coal, well-developed micro-cracks and micro-pores can be observed with less obstruction, permeability is good. The pores are mainly airtight with a close end or cylindrically connected, little ink-bottle pores are found, illustrating a strong tectonic stress on the coal. Dissolution pores dominate after immersion of the coal in the saturated water, leading to round surface covered by many particulate matters, as well as slightly decreased pore surface area and pore volume, accounting for dissolution of minerals into the saturated water. In presence of the saturated drilling fluid, pore area and pore volume corresponding to the above pore diameters decline greatly. Round surface with little coverage of particulate matters and majority of pores filled with particles can be identified, resulting in almost completely airtight pores with a close end, demonstrating drilling fluids adsorption to coal and blockage occurred. Large quantity of micro-pores and transitional pores are beneficial for gas adsorption in the coals. It is necessary to add appropriate plugging materials and proper amount of surfactants into the drilling fluids to seal cracks and pores in the coal, reducing drilling fluids invasion and destroy to side wall of drilling holes.

\section{Introduction}

Many studies show that performance of drilling fluid (such as drilling fluid density, viscosity, rheological properties, lubricity and suppression, etc.) have great influence on drilling safety of the coal mine ${ }^{[1-3]}$. Due to the intrusion of different fluid into the coal and rock have a great influence on its surface pore structure, so it is necessary to make further research on the impact of different fluids on its surface pore structure and stability ${ }^{[4-5]}$. In this paper, scanning electron microscopy (SEM), mercury injection and low-temperature nitrogen sorption-desorption experiments were performed to investigate microscopic pore characteristics and its geological accumulation significance of the coal bed. 


\section{Experimental}

Coal samples and drilling is provided by China Petroleum Group Drilling Engineering Technology Research Institute. Coal samples were collected from Baode coal mines of Hedong coalfield in shanxi province. The coal rank of the coal sample is 0.837 .

\section{Results and Discussion}

Physical adsorption experiments were carried out by ASAP2020 instrument, specific surface area were calculated by BET method, using BJH method to calculate the pore size distribution, pore volume and average pore diameter, using t-plot method to calculate the pore volume and micropore area. The results are shown in Figures 1 and 2.

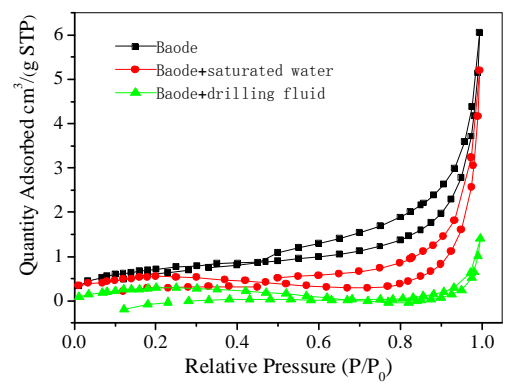

Figure 1 Nitrogen adsorption isotherm curves

It can be seen from Figure 1 that when relative pressure is below 0.4, the adsorption and desorption branches almost coincide, showing mostly end-closed holes with impermeable pore structure in smaller pore size range. Curves is slightly raised to $\mathrm{Y}$ axis in the relative pressure of 0 0.1 , illustrating more micropores and some strong interaction between nitrogen gas and the coal samples. When relative pressure closes to the saturated vapor pressure, curves rise sharply, indicating some cracked macropores in the samples.

With increase of relative pressure, curves of raw coal samples rise gently. Relative pressure locate at 0.4 to 1 , the adsorption and desorption branches separate, forming adsorption loop. At relative pressure of 0.5 , desorption branches appear a drop then flatten, indicating formed flask-shaped pore structure. Compared with raw coal samples, adsorption volume of coal samples treated with saturated water are slightly lowered with broadened adsorption loop, indicating wider pore size distribution. Coal samples treated with saturated drilling fluid has a significant decline in adsorption capacity. In relative pressure range of $0-0.9$, curves change gently, approximately parallel to the $\mathrm{X}$ axis, the adsorption and desorption branches almost overlap, attributed to relatively uniform shape and size, and few or no mesoporous structure existed.
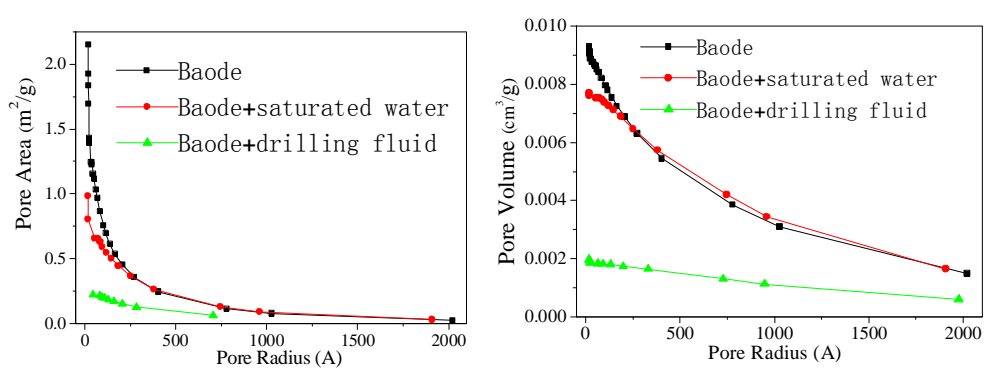

Figure 2 Cumulative BJH pore volume and pore surface area

According to Figure 2, accumulation of surface area increases slowly when pore size is more than $20 \mathrm{~nm}$, a sharp increase in the surface area of the pore correspond to the pore size less than 
$15 \mathrm{~nm}$. A greater contributions has been made to the total surface area of the samples by micropores in the sample (pore size less than $15 \mathrm{~nm}$ ), showing large quantity of micropores in the sample. BJH pore volume cumulative distribution also illustrate that majority of pores size is less than $20 \mathrm{~nm}$, which is useful to migration of oil and gases in the coal bed.

As a result, drilling fluid has a greater influence on the pore structure of coal samples. Baode coal adsorption pore distribution is mainly in range of $5-10 \mathrm{~nm}$. Addition of drilling fluid leads to a great decline in pore volume and surface area. No evident decreasing trend in pore area and pore volume is observed with saturated water addition, revealing that the drilling fluid has a certain protective effect on the coal and rock.

SEM observation of the coal samples were obtained as shown in Figures 3, respectively.

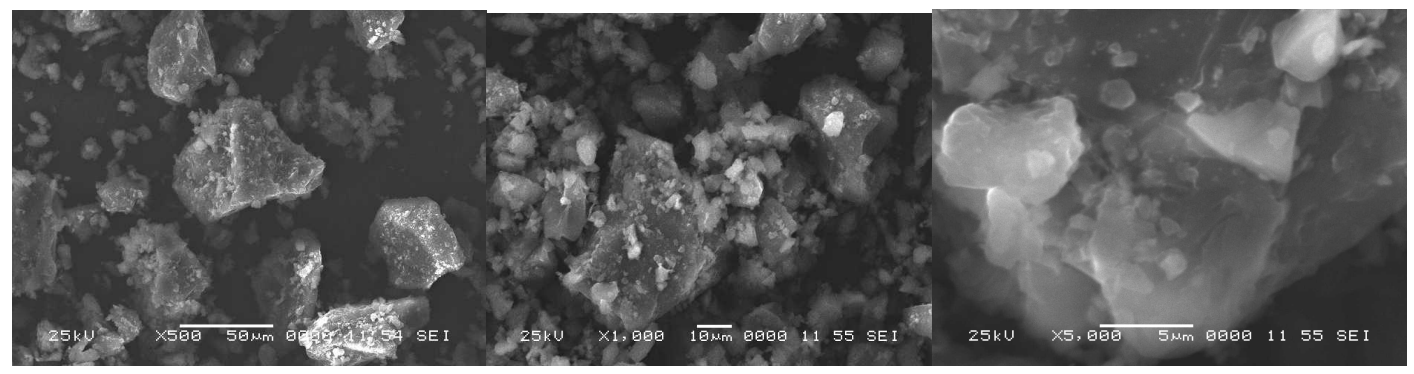

(a) Raw coal samples

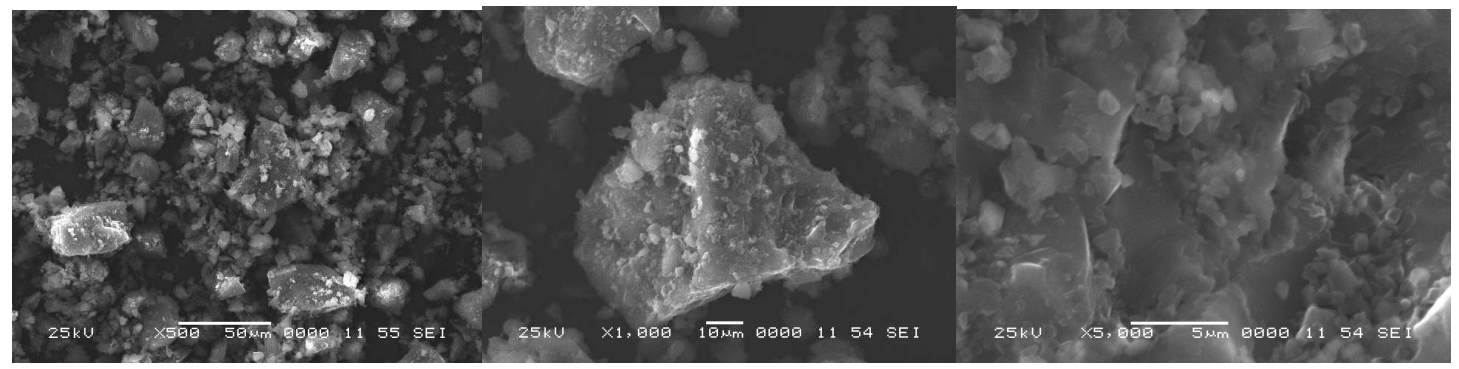

(a) Coal samples treated with saturated water

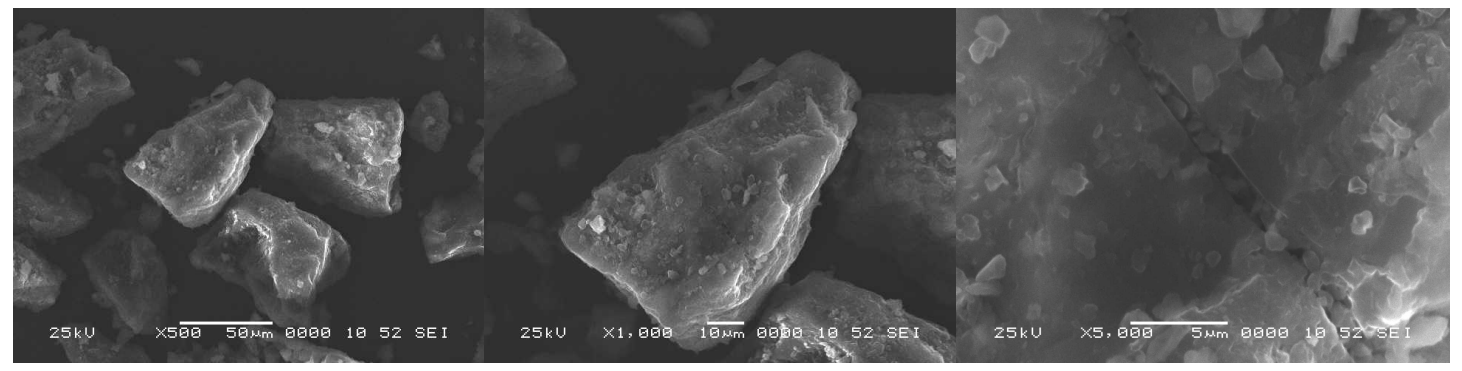

(b) Coal samples treated with drilling fluid

Figure 3 SEM photos of Baode coal samples

It can be seen from Figure 3 that there are lots of micro-cracks and micro pores in Baode coal sample, particle size is $1-10 \mu \mathrm{m}$, large amount of particles do not fill into the cracks and pores. Treated with saturated water, the particles appear as irregular lumps with pits on the surface. Drilling fluid bring about micro-crack with width about $1 \mu \mathrm{m}$, which distribute uniformly and is filled with small particles, forming abundant nibs pores.

\section{Conclusions}

Intergranular pores and transitional pores are main types, accompanied by obvious oval shaped pores and friction pores in Baode coal, well-developed micro-cracks and micro-pores can be observed with less obstruction. The pores are mainly airtight with a close end or cylindrically 
connected, little ink-bottle pores are found, illustrating a strong tectonic stress on the coal. Dissolution pores dominate after immersion of the coal in the saturated water, leading to round surface covered by many particulate matters, as well as slightly decreased pore surface area and pore volume, accounting for dissolution of minerals into the saturated water. In presence of the saturated drilling fluid, pore area and pore volume corresponding to the above pore diameters decline greatly. Round surface with little coverage of particulate matters and majority of pores filled with particles can be identified, resulting in almost completely airtight pores with a close end, demonstrating drilling fluids adsorption to coal and blockage occurred. Large quantity of micro-pores and transitional pores are beneficial for gas adsorption in the coals.

\section{Acknowledgement}

This work was supported by the Natural Science Basic Research Plan in Shaanxi Province of China (No.2015JM5168) and Technological Innovation Projects of Shenhua Ningxia Coal Industry Group Co., Ltd.

\section{References}

[1] Bingzhong Shi, Yongxue Lin. Sinopec drilling technology progress and development direction[J]. Drilling Fluid and Completion Fluid, 2013,30(2): 77-82.

[2] Zhonghua Wang. Drilling fluid technology progress at home and abroad and the understanding of drilling fluid[J]. Chinese and Overseas Energy, 2011, 16(1): 48-59.

[3] Lingling Qi, Zhaofeng Wang, Hongmin Yang, XiangJun Chen. The research of coal sample pore Based on the low-temperature nitrogen adsorption method and the mercury intrusion method[J]. Coal Science and Technology, 2012, 40(8): 36-39.

[4] Jinmei Chen, Ping Tan, Jianyong Wang. Gas adsorption characterization of specific surface area and pore structure of porous materials[J]. Powder Metallurgy Industry, 2011, 21(2): 45-49.

[5] Shuheng Tang, Jingping Zhang, Minjie Wu. Sapropelic coal pore structure characteristics research[J]. Natural Gas in Earth Science, 2013, 24(2): 247-251. 